\title{
Epiduroscopic Assisted Percutaneous Endoscopic Lumbar Discectomy: A Technical Report
}

Gun Choi, Priyank Uniyal ${ }^{*}$, Wook Ha Kim, Zohier Hassan, Bhupesh Patel and JH Lee

Wooridul Spine Hospital, Pohang, Korea

*Corresponding author: Priyank Uniyal, Wooridul Spine Hospital, Pohang, Korea, Tel: +82 54240 6129; Fax: +82-54-240-6195; E-mail: priyank_uniyal@yahoo.com Rec date: Sep 24, 2016; Acc date: Oct 06, 2016; Pub date: Oct 15, 2016

Copyright: @ 2016 Choi G, et al. This is an open-access article distributed under the terms of the Creative Commons Attribution License, which permits unrestricted use, distribution, and reproduction in any medium, provided the original author and source are credited.

\begin{abstract}
The Authors report a new technique with trans sacral epiduroscopy assisted Percutaneous Endoscopic Lumbar Discectomy (PELD) for high grade centrally down migrated lumbar disc herniation. When the chances of missing the disc fragments are high, as in the cases of down migrated disc herniations by conventional transforaminal PELD, it can be assisted by sacral epiduroscopy for the complete removal and confirmation of any remnant disc fragments.
\end{abstract}

Keywords: Sacral epiduroscopy; Percutaneous endoscopic Lumbar discectomy; High grade centrally down migrated lumbar disc herniation

\section{Introduction}

These days, all disc herniations and other pathologies in the lumbar spine can be operated by full endoscopic techniques [1-14]. Earlier in 1987, Kambin [15] described and illustrated "triangular safe zone" from the posterolateral approach in the lumbar spine. Since then there has been numerous advancement in the spine endoscopy.

Access through the sacral hiatus with a flexible endoscope, has been developed to allow an alternative, longitudinal, approach to the entire lumbar epidural space [16]. Through the endoscope, surgical instruments including laser waveguide fibers, stimulating catheters and endoscopic forceps can be introduced for diagnostic and therapeutic means. Epiduroscopy was first introduced in 1931 by Burmann who examined the epidural space via endoscope [17], but it would be decades before the technology was put to use for a wider range of clinical applications including adhesiolysis and neuroplasty as popularized by Racz [18]. In 1991, Heavner used a flexible fiberscope, as well as optical instruments to perform epiduroscopy [19].

The procedure using an epiduroscope has gradually been generalized because it has drawn attention as a tool for diagnosing chronic low back pain [20,21]. Jo and Yang [20] asserted that epiduroscopy is a useful tool in investigating the causes of low back pain because it is not only for the treatment of refractory back pain but also as a diagnostic tool for low back pain, and predicted that the application of epiduroscopy would increase with development of better optics.

As the least invasive technique for patients with lumbar disc extrusion or spinal stenosis, epiduroscopy (which approaches the herniated disc via the sacral hiatus) enables surgeons to do so with only a small incision at S4. Through that dissection, the flexible endoscope enables clinicians to move freely and visualise within the epidural space from the sacrum to the lumbar region. This epiduroscopy can be combined with transforaminal percutaneous endoscopic lumbar discectomy (PELD) for high grade down migrated disc herniation when the chances of missing the fragments are too high, for the complete removal under direct visualization.

\section{Selection of the Patient}

\section{Inclusion criteria}

- Contained and non-contained high grade down migrated lumbar disc herniation

- Synovial or discal cyst

- Failure to improve after 3 weeks of conservative management

\section{Contraindications}

- Spondylolisthesis

- Calcified disc on CT scan

- Significant collapsed Intervertebral disc space

- Infections

- Canal stenosis

- Sacral perineural cyst

- Hemorrhagic diasthesis

\section{Technical aspects}

Approach: Trans-sacral and Transforaminal (lumbar).

\section{Armamentarium}

- Endoscope - New lumbar endoscopic spine system (Spine doctors, South Korea).

- Angle: 30 degrees

- Length: $208 \mathrm{~mm}$

- Working channel: $4.2 \mathrm{~mm}$

- Outer diameter: $6.5 \mathrm{~mm}$

- Spinal Needle: 18 Gauge 7.5 inches.

- Guide wire: $0.8 \mathrm{~mm}$.

- Obturator: $6.5 \mathrm{~mm}$.

- Cannula: $7.5 \mathrm{~mm}$. 
Citation: Choi G, Uniyal P, Kim WH, Hassan Z, Patel B, Lee JH, et al. (2016) Epiduroscopic Assisted Percutaneous Endoscopic Lumbar Discectomy: A Technical Report. J Neurol Disord 4: 306. doi:10.4172/2329-6895.1000306

Page 2 of 5

- Endoscopic grasper forceps - working length is $320 \mathrm{~mm}$ and diameter is $3.5 \mathrm{~mm}$ (Figure A).

- Radiofrequecy cautery RF (Trigger Flex Elliquence, USA).

- Ho-YAG laser with side firing probe (VersaPulse Lumenis 100W).

- A blunt tip probe.

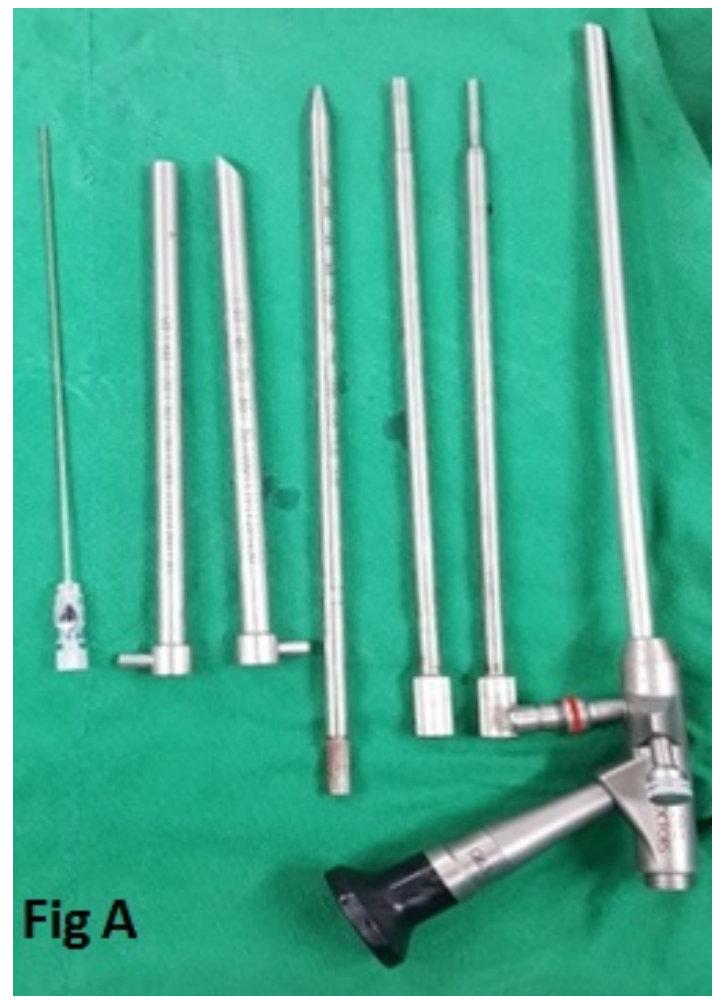

Figure A: Transforaminal PELD set.

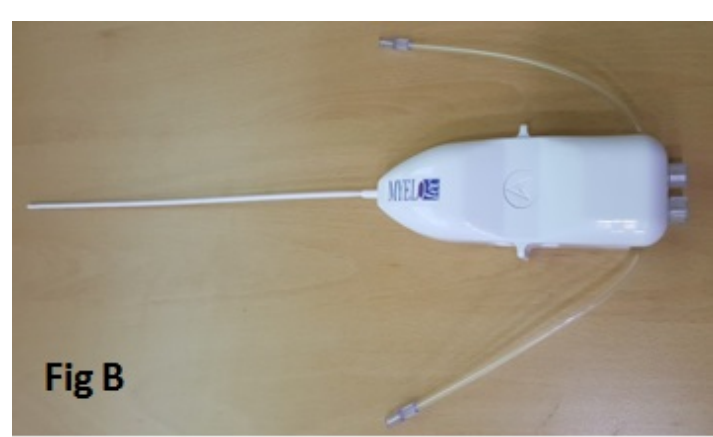

Figure B: Video guided catheter (VGC).

\section{Myelotec epiduroscopy set (Roswell, GA)}

- Touhy needle.

- Video guided catheter (VGC) $3.0 \mathrm{~mm}$ outer diameter (1.3 dual working channels and dual infusion ports for infusion saline for irrigation) (Figure B).

- Flexible fiberoptic scope 1.2 outer diameter.

- Ho-YAG laser end firing fibre probe $2.3 \mathrm{~F}$ outer diameter.

\section{Technique}

Anaesthesia: Under sacral epidural block for epiduroscopy \& local anaesthesia with conscious sedation (initially intravenous Midazolam $0.05 \mathrm{mg} / \mathrm{kg}$ and $0.8 \mathrm{mg} / \mathrm{kg}$ Fentanyl and repeated if required) for transforaminal PELD.

Position: Prone position with hips and knees in flexion on a radiolucent Jackson table.

For epiduroscopy a $5 \mathrm{~mm}$ skin incision is made over the sacral hiatus using an 11 number blade. The sacrococcygeal ligament is punctured with a Tuohy needle under fluoroscopic guidance and the Myelotec catheter is inserted into the sacrococcygeal ventral epidural space. Subsequently, a $3.0 \mathrm{~mm}$ steerable VGC is introduced and the catheter is advanced into the lumbar epidural space under $\mathrm{C}$-arm anterior/posterior (A.P) and lateral views. An Epidurogram is performed which will show the obstruction at the herniated disc level. Through VGC, an epiduroscope and the Ho: YAG laser is introduced and the herniated disc is identified between Posterior longitudinal ligament (PLL) and the posterior annulus. Once the fragments are identified transforaminal endoscopy is performed.

For transforaminal PELD, starting point of needle Insertion from skin is decided from preoperative MRI and CT scans. Skin is infiltration with $8 \mathrm{ml}$ to $10 \mathrm{ml} 1 \%$ lidocaine, skin, deep tissue (1-2 ml for skin and subcutaneous tissue, 7-9 $\mathrm{ml}$ for deep infiltration). A $18 \mathrm{G}$ 7.5 inch spinal needle is inserted through posterolateral approach into the pathological disc space upto the midpedicular line on A.P view and posterior vertebral line on lateral view (Figures la and 1b). A discography is performed (mixture of contrast and dye omnipaque: indigocarmine : normal saline - 2:1:2 respectively) and a blunt tip guide wire of $0.8 \mathrm{~mm}$ is exchanged with the spinal needle followed by a $7 \mathrm{~mm}$ stab incision over the guide wire.

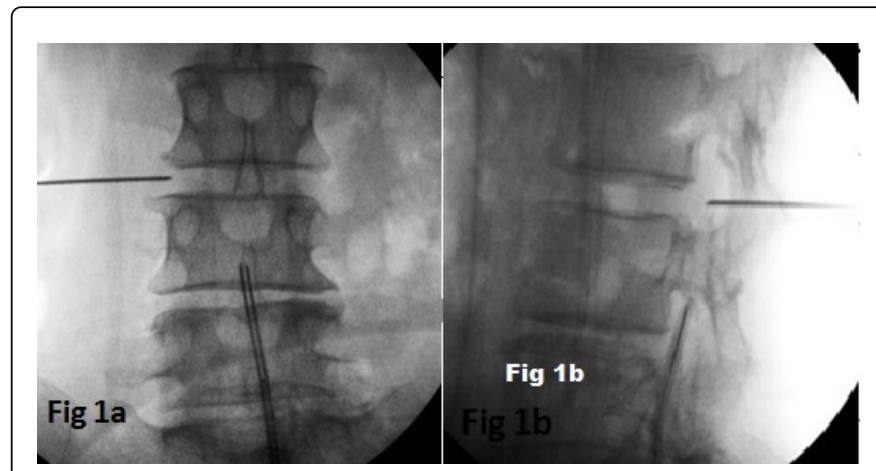

Figure 1: Spinal needle and epiduroscope placement in 1a- A.P view $1 \mathrm{~b}$ - lateral view.

Obturator and cannula placement: A $6.5 \mathrm{~mm}$ obturator with a tapered end is passed over the guide wire. Tapered end of the obturator facilitates the easy insertion, now guide wire is removed and a $7.5 \mathrm{~mm}$ bevelled cannula is passed over the obturator. The obturator is removed and the bevel of the cannula is kept facing to the epidural space (half into the epidural space and half into the posterior annulus) (Figure 2). 
Citation: Choi G, Uniyal P, Kim WH, Hassan Z, Patel B, Lee JH, et al. (2016) Epiduroscopic Assisted Percutaneous Endoscopic Lumbar Discectomy: A Technical Report. J Neurol Disord 4: 306. doi:10.4172/2329-6895.1000306

Page 3 of 5

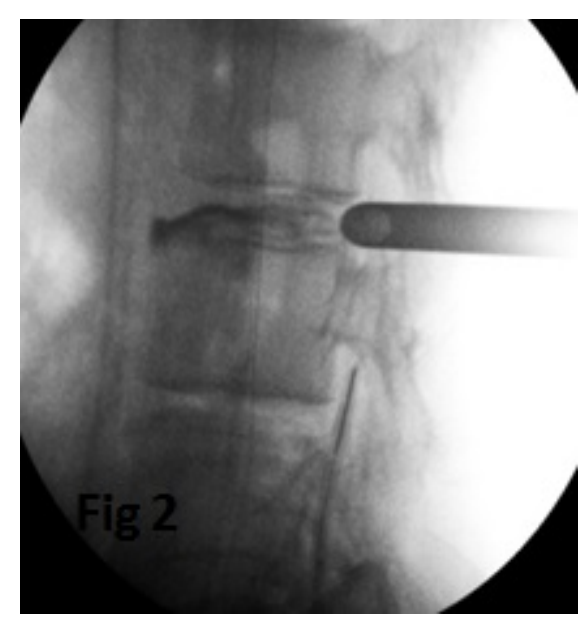

Figure 2: Transforaminal PELD cannula insertion after discography.

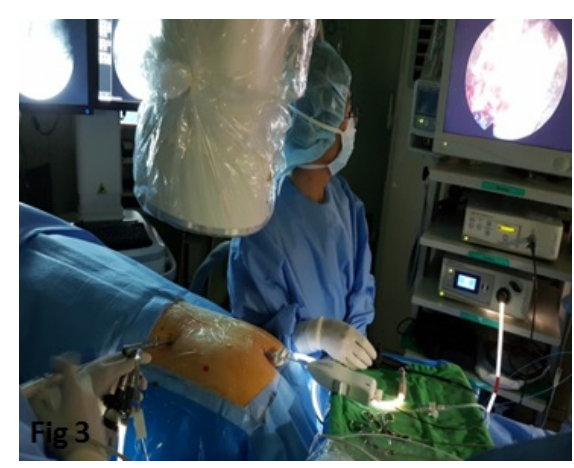

Figure 3: Sacral epiduroscopy and Transforaminal PELD have been performed simultaneously.

Endoscopy and fragmentectomy: A $6.5 \mathrm{~mm}, 30$ Degree rigid working channel endoscope (Spine Doctors, South Korea) is introduced into the cannula (Figure 3). Epidural vessels are coagulated with RF and hemostasis is achieved. If required posterior annulus and PLL complex is released to identifiy the tail of herniated disc fragment. With the help of Ho-YAG laser and a blunt probe or a flexible hook the herniation is teased out and made free from the mouth of the annular entrapment. Disc fragments are removed with an endoscopic grasper forceps. At the same time trans scaral epiduroscopy is performed for the confirmation of the complete removal and for residual fragments. If remaining fragments or any adhesions are noticed, they are vapourised and released by the end firing Ho-YAG laser. The transforaminal illumination of endoscope can be well visualized by trans-sacral endoscopy (Figure 4). Once the free floating epidural fat or thecal sac is visualized the transforaminal endoscope is removed. Epidurogram is performed which will show a flattened outline of the herniation and free flow of dye at the previous pathological level. Both of the skin entry sites for sacral epiduroscopy and transforaminal PELD is closed with ethilon 3-0. A preoperative and postoperative MRI of a case is illustrated in (Figures 5 and 6).

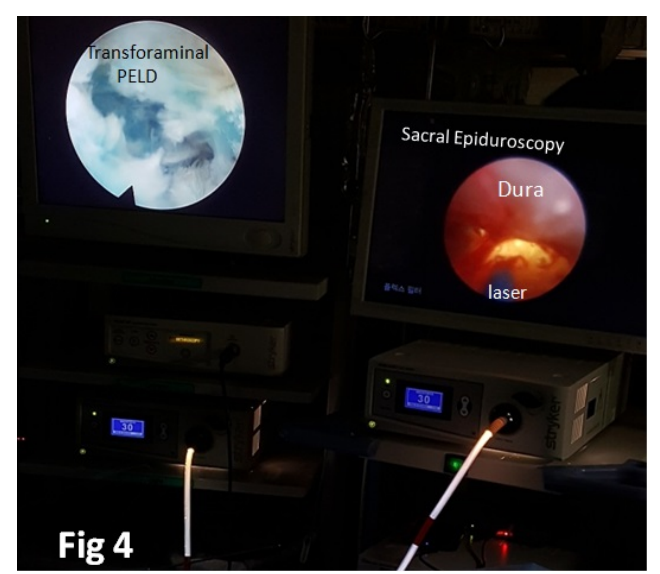

Figure 4: Screen on the left shows transforaminal endoscopic view in which annular and blue stained disc fragment can be appreciated. Screen on the right- epiduroscopic view showing ablation of remnant disc by Ho-YAG laser probe and confirmation of complete decompression. The transillumination of the transforaminal endoscopy is well visualized at the centre of the epiduroscopic view on the right screen.

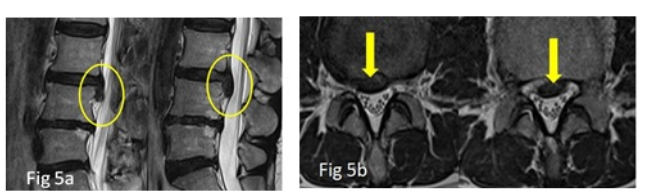

Figure 5: Preoperative MRI (5a: sagittal scans show L3-L4 down migrated disc herniation, 5b: Axial scans showing central down disc herniation up to the inferior pedicle margin).

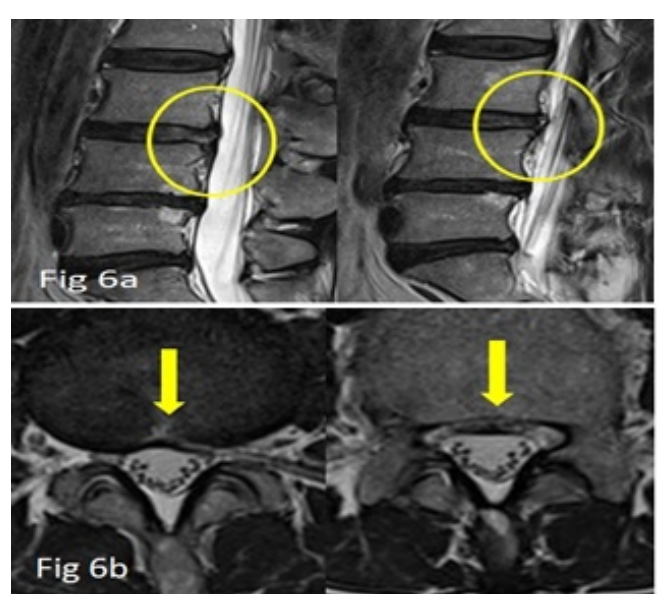

Figure 6: Post-operative MRI, 6a and 6b: shows complete removal of the down migrated disc herniation after epiduroscopic assisted transforaminal PELD. 


\section{Discussion}

The epidural space is a potential space filled with epidural fat between the dura and the bone and ligament of the spinal canal [22]. The pathology that leads to nerve root compression, such as intervertebral disc rupture, typically lies within this space. Approaches to the lumbar epidural space must be within the anterior or posterior epidural space. Below the conus medularis, the cauda equina is freely mobile, and frequently there is ample room to manoeuvre a small flexible endoscope or other instrumentation.

In 1991, Schaffer and Kambin reported another technique called arthroscopic microdiscectomy [23]. These methods enable surgeons to operate percutaneously, to minimize the incision, limit damage to normal tissues, reduce post-operative instability, reduce degenerative progression, and decrease the likelihood of epidural fibrosis. Johansen and Smith, and Owens et al. cited surgical benefits of using laser treatment for lumbar disc extrusion with outstanding treatment results $[24,25]$.

In this article, we describe another possible indication for sacral epiduroscopic approach by combining this approach with a conventional Transforaminal endoscopy for the case of high migrated lumbar disc herniation to ensure complete removal of the herniated fragment and complete decompression of nerve root. Lim et al. [26] has recently shown a prospective case series for the effective treatment of lumbar disc herniation by epiduroscopy. The lumbar disc migrations which are centrally down migrated are extremely challenging to deal with only by transforaminal approach even after foraminoplasties and by various other approaches. Therefore, most spine surgeons prefer open procedures which require extensive removal of pars and facet leading to the risk of instability. In our institute we manage such cases by this combined approach of sacral epiduroscopic assisted transforaminal PELD.

But again, it requires a long learning curve and expertise for the surgeon. The major disadvantages [26] of the epiduroscopy are the narrow epiduroscopic view and unclear image quality in the narrow epidural space, which occasionally impaired visibility and limited the ablation of soft tissue with the end firing laser. With more advancement in the optics and design of the sacral epidural endoscope this procedure will become more feasible for most of the endoscopic spine surgeons.

\section{Conclusion}

Epiduroscopic assisted transforminal PELD is a good alternative for difficult PELD's when there is high grade disc migration and chances of missing the fragments are high. It is performed as an outpatient procedure and patient can be discharged same day from the hospital.

\section{References}

1. Kambin P, Casey K, O`Brien E, Zhou L (1996) Transforaminal arthroscopic decompression of the lateral recess stenosis. J Neurosurg 84: 462-467.

2. Kambin P, Zhou L (1996) History and current status of percutaneous arthroscopic disc surgery. Spine 21: 57-61.

3. Lew SM, Mehalic TF, Fagone KL (2001) Transforaminal percutaneous endoscopic discectomy in the treatment of far-lateral and foraminal lumbar disc herniations. J Neurosurg 94: 216-220.
4. Savitz MH (1994) Same-day microsurgical arthroscopic lateral-approach laser-assisted (SMALL) fluoroscopic discectomy. J Neurosurg 80: 1039-1045.

5. Tsou PM, Yeung AT (2002) Transforaminal endoscopic decompression for radiculopathy secondary to intracanal noncontained lumbar disc herniations: outcome and technique. Spine J 2: 41-48.

6. Yeung AT, Tsou PM (2002) Postero-lateral endoscopic excision for lumbar disc herniation: Surgical technique, outcome and complications in 307 consecutive cases. Spine 27: 722-731.

7. Ruetten S, Komp M, Godolias G (2006) A new full-endoscopic technique for the interlaminar operation of lumbar disc herniations using $6 \mathrm{~mm}$ endoscopes: Prospective 2-year results of 331 patients. Minim Invas Neurosurg 49: 80-87.

8. Ruetten S, Komp M, Godolias G (2005) Full-endoscopic interlaminar operation of lumbar disc herniations using new endoscopes and instruments. Orthop Praxis 10: 527-532.

9. Ruetten S (2005) The full-endoscopic interlaminar approach for lumbar disc herniations. Minimally Invasive Spine Surgery 346-355.

10. Ruetten S, Meyer O, Godolias G (2003) Endoscopic surgery of the lumbar epidural space (epiduroscopy): results of therapeutic intervention in 93 patients. Minim Invasive Neurosurg 46: 1-4.

11. Ruetten S, Meyer O, Godolias G (2002) Application of holmium: YAG laser in epiduroscopy: extended practicabilities in the treatment of chronic back pain syndrome. J Clin Laser Med Surg 20: 203-206.

12. Ruetten S, Godolias G (2002) Possibilities of epiduroscopy in the treatment of chronic back pain syndrome using holmium laser and instruments. First results of 53 patients having had no previous surgical treatment. Orthop Praxis 38: 315-318.

13. Ruetten S, Meyer O, Godolias G (2002) Epiduroscopic diagnosis and treatment of epidural adhesions in chronic back pain syndrome of patients with previous surgical treatment: first results of 31 interventions. Z Orthop 140: 171-175.

14. Ruetten S, Komp M, Godolias G (2005) An extreme lateral access for the surgery of lumbar disc herniations inside the spinal canal using the fullendoscopic uniportal transforaminal approach. Technique and prospective results of 463 patients. Spine 30: 2570-2578.

15. Kambin P, Brager MD (1987) Percutaneous posterolateral discectomy. Anatomy and mechanism Clin Orthop Relat Res Oct; 223: 145-154.

16. Richter EO, Abramova MV, Mussell JC (2011) Current trends in minimally invasive spinal surgery. J Neurosurg Rev 1: 1-13.

17. Burmann M (1931) Myeloscopy or the direct visualization on the spinal cord. J Bone Joint Surg 13: 695-696.

18. Racz G, Heavner J, Raj P (1997) Epidural neuroplasty. Seminars in Anesthesia 16: 302-312.

19. Heavner J, Chokhavatia S, Kizelshteyn G (1991) Percutaneous evaluation of the epidural and subarachnoid space with a flexible fiberscope. Reg Anesth 15 (1): 85.

20. Jo DH, Yang HJ (2013) The survey of the patient received the epiduroscopic laser neural decompression. Korean J Pain 26: 27-31.

21. Richter EO, Abramova MV, Cantu F, De Andres J, Lierz P, et al. (2011) Anterior epiduroscopic neural decompression: eight-center experience in 154 patients. Eur J Pain 5: 401-407.

22. DeAndres J, Angel Reina M, Maches F, Garcia de Sola R, Oliva A, et al. (2011) Epidural Fat: Considerations for minimally invasive spinal injection and surgical therapies. J Neurosurg Rev 1: 45-53.

23. Schaffer JL, Kambin P (1991) Percutaneous posterolateral lumbar discectomy and decompression with a 6.9-millimeter cannula. Analysis of operative failures and complications. J Bone Joint Surg Am 73: 822-831.

24. Owens P, Emmons W, Owens $\mathrm{T}$ (1988) Differential recovery rates between laser versus non-laser lumbar laminectomy patients. Lasers Surg Med 8: 196.

25. Johansen W, Smith C, Vangness C (1986) Comparison of percutaneous laser discectomy with other modalities for the treatment of herniated lumbar discs and cadaveric studies of percutaneous laser discectomy. Int Soc Opt Eng 712: 218. 
Citation: Choi G, Uniyal P, Kim WH, Hassan Z, Patel B, Lee JH, et al. (2016) Epiduroscopic Assisted Percutaneous Endoscopic Lumbar Discectomy: A Technical Report. J Neurol Disord 4: 306. doi:10.4172/2329-6895.1000306

Page 5 of 5

26. Lee SH, Lee SH, Lim KT (2016) Trans-Sacral epiduroscopic laser decompression for symptomatic lumbar disc herniation: A preliminary case series. Photomed Laser Surg 34: 121-129. 